\title{
Kinetics, energetics and specificity of a general amino acid transporter from the ectomycorrhizal fungus Paxillus involutus
}

\author{
Michel Chalot, ${ }^{1,2}$ Annick Brun, ${ }^{1,2}$ Bernard Botton ${ }^{2}$ \\ and Bengt Soderstrom ${ }^{1}$
}

1 Department of Microbial Ecology, University of Lund, S-223 62 Lund, Sweden

2 Laboratory of Forest Biology, U.A. INRA 977, University Henri Poincaré, Nancy I, Faculty of Sciences, F-54506

Vandœuvre Cedex, France

\author{
Author for correspondence: Michel Chalot. Tel: +33839127 38. Fax: + 3383903277. \\ e-mail : chalot@scbiol.u-nancy.fr
}

\begin{abstract}
The kinetics, energetics and specificity of a general amino acid transporter were studied in the ectomycorrhizal fungus Paxillus involutus (Batsch) Fr. The uptake of amino acids showed features characteristic of active transport. After correction for a non-mediated transport component, the kinetics of glutamate, glutamine, alanine and aspartate uptake measured over a wide concentration range followed the simple Michaelis-Menten saturation curves. The apparent $K_{m}$ derived from the Eadie-Hofstee plots ranged from $7 \mu \mathrm{M}$ for alanine to $27 \mu \mathrm{M}$ for glutamate. Dinitrophenol, carbonyl cyanide $m$-chlorophenylhydrazone and $\mathrm{NaN}_{3}$ strongly inhibited amino acid uptake, whereas dicyclohexylcarbodiimide, vanadate and the ionophores monensin and nonactin had no effect on the uptake. Both pH dependence and inhibition by protonophores are consistent with a proton symport mechanism for amino acid uptake by $P$. involutus. Competition studies indicated a broad substrate recognition by the uptake system, which resembles the general amino acid permease of yeast. Dixon plots of the inhibition of glutamate uptake by alanine, lysine and methionine sulfoximine showed that inhibitions were competitive. The physiological importance of this transporter for the exchange of nitrogenous compounds between fungal and host plant cells in ectomycorrhizal associations is discussed.
\end{abstract}

Keywords: amino acid uptake, competition and inhibition experiments, ectomycorrhizal fungus, proton symport mechanism, Paxillus involutus

\section{INTRODUCTION}

Ectomycorrhizal fungi are capable of utilizing peptides and amino acids as nitrogen sources (Abuzinadah \& Read, 1986, 1988; Finlay et al., 1992); for instance, glutamate and glutamine can support biomass production comparable to that on ammonium for different ectomycorrhizal fungi (Abuzinadah \& Read, 1988; Chalot $e t$ al., 1991; Finlay et al., 1992). Although ammonium nutrition and metabolism of ectomycorrhizal fungi have received considerable attention (for review, see Martin \& Botton, 1993; Botton \& Chalot, 1995), less has been given to the utilization of amino acids by ectomycorrhizal fungi.

Abbreviations: ALB, albizziin; AOA, aminooxyacetate; CCCP, carbonyl cyanide $m$-chlorophenylhydrazone; DCCD, dicyclohexylcarbodiimide; DNP, 2,4-dinitrophenol; MSX, methionine sulfoximine.
We have previously reported that glutamate, glutamine and alanine are readily metabolized by Paxillus involutus (Batsch) Fr. by the activity of glutamine synthetase, glutamate synthase and alanine aminotransferase, respectively (Chalot et al., 1994a, b, 1995a, b). Uptake of glutamate and glutamine had a distinct $\mathrm{pH}$ optimum around $\mathrm{pH} 4.0$ and declined sharply between $\mathrm{pH} 4.5$ and 6.4. Uptake of alanine and aspartate was also highest at low $\mathrm{pH}$ values (3-4) but declined more slowly with increasing $\mathrm{pH}$ (Chalot et al., 1995a). The total uptake of labelled amino acids was unaffected by exogenously supplied ammonium, nitrate or glucose. These results lend strong support to the idea that uptake processes for organic and inorganic nitrogen sources operate quite independently, as discussed by Schobert \& Komor (1987).

However, no information is available on the amino acid transport system(s) in ectomycorrhizal fungi, whereas it has been widely studied in higher plants (Bush, 1993; 
Frommer et al., 1994), yeasts and non-mycorrhizal fungi (Ramos et al., 1980; Barran, 1981; Horak, 1986; Roos, 1989; Sophianopoulou \& Diallinas, 1995). In eukaryotes, the uptake of amino acids is brought about by a variety of carriers, most of them being specific for one or a few related L-amino acids and exhibiting different properties with respect to substrate affinity, specificity, capacity and regulation (Roos, 1989; Bush, 1993); for instance, many higher plant, algal and fungal tissues seem to have an apparently specific carrier for basic amino acids (Johannes \& Felle, 1985; Sauer \& Tanner, 1985; Roos, 1989; Bush, 1993). It has been proposed that three different permeases are involved in the uptake of basic amino acids by Saccharomyces cerevisiae: GAP1 is the general permease transporting all amino acids, CAN1 is a transport system specific for basic amino acids and their analogues, and LYP1 is a strictly lysine-specific permease (Horak, 1986). However, the broadest specificity is offered by the general amino acid permease, which mediates the uptake of most $\mathrm{L}$ - and D-amino acids, non-protein amino acids and a number of toxic amino acid analogues or amino acid biosynthesis inhibitors (Wiame et al., 1985; Horak, 1986; Roos, 1989; Sophianopoulou \& Diallinas, 1995).

There is convincing evidence that the immediate source of energy driving amino acid uptake is a proton electrochemical gradient across the plasma membrane. This energy is utilized to drive the uphill transport of amino acids, i.e. against their own concentration gradient. The uptake of most of the amino acids in higher plants and yeasts is therefore coupled to $\mathrm{H}^{+}$-cotransport (Sanders $e t$ al., 1983; McCutcheon \& Bown, 1987; Roos, 1989; Bush, 1993).

Glutamate, glutamine, aspartate and alanine are amongst the most important free amino acids in soil, their concentration ranging between 1 and $10 \mu \mathrm{g}(\mathrm{g} \text { dry soil })^{-1}$ (Abuarghub \& Read, 1988). They are also likely to be the main candidates for transfer of amino acids between fungal cells and host cells in ectomycorrhizal symbiotic tissues (Smith \& Smith, 1989; Chalot et al., 1991; Martin \& Botton, 1993). For these reasons, these four amino acids were chosen to study the kinetic and energetic properties of a general amino acid transporter in the ectomycorrhizal fungus $P$. involutus. Of special interest was the specificity and the examination of possible effects of metabolic inhibitors on amino acid uptake.

\section{METHODS}

Chemicals. The ${ }^{14} \mathrm{C}$-labelled amino acids were obtained from New England Nuclear (Du Pont de Nemours). Carbonyl cyanide $m$-chlorophenylhydrazone (CCCP), 2,4-dinitrophenol (DNP), dicyclohexylcarbodiimide (DCCD), nonactin and monensin were purchased from Sigma. Soluene 350 and Ionic Fluor were obtained from Packard Instrument. Unlabelled amino acids and other chemicals were of analytical grade.

Organism and growth conditions. The ectomycorrhizal fungus used was an isolate of Paxillus involutus (Batsch) Fr. (ATCC 200175 , no. 87.017 in the culture collection of the Department of Microbial Ecology in Lund, Sweden), which was originally isolated from fruit bodies associated with 15-30-year-old Betula pendula trees growing on coal waste in Midlothian, Scotland, UK. It was grown on cellophane-covered agar medium containing modified Melin-Norkrans medium (MMN) from which malt extract was omitted. The MMN medium (Marx, 1969) contained (mg l-1): $\mathrm{KH}_{2} \mathrm{PO}_{4}(500),\left(\mathrm{NH}_{4}\right)_{2} \mathrm{HPO}_{4}(250)$, $\mathrm{CaCl}_{2}(50), \mathrm{NaCl}(25), \mathrm{MgSO}_{4} \cdot 7 \mathrm{H}_{2} \mathrm{O}$ (150), thiamin hydrochloride $(0 \cdot 1), \mathrm{FeCl}_{3} \cdot 6 \mathrm{H}_{2} \mathrm{O}(1)$. This medium was used with $1 \mathrm{~g}$ glucose $1^{-1}$.

Uptake experiments. In the standard assay, discs of fungal mycelium were cut from the actively growing edge of 10-d-old colonies using a $25 \mathrm{~mm}$ diameter cork borer. The discs were floated for $5 \mathrm{~min}$ on a solution containing $1 \mathrm{ml}$ nitrogen- and glucose-free $\mathrm{MMN}(\mathrm{pH} 4 \cdot 2)$ at $25^{\circ} \mathrm{C}$ supplemented with different ${ }^{14} \mathrm{C}$-labelled amino acids. This $\mathrm{pH}$ was selected because it is near the optimal $\mathrm{pH}$ value for glutamate, glutamine, alanine and aspartate uptake (Chalot et al., 1995a). Uptake of ${ }^{14} \mathrm{C}$ labelled amino acids into the mycelium was linear for at least $45 \mathrm{~min}$ for the four amino acids used. However, a short-term incubation of $5 \mathrm{~min}$ was chosen in order to avoid underestimation of the ${ }^{14} \mathrm{C}$-labelled amino acid uptake due to subsequent metabolism and to ${ }^{14} \mathrm{CO}_{2}$ evolution. We have previously calculated that the respiratory loss of carbon from glutamate, glutamine and alanine accounted for 9,6 and $15 \%$, respectively, of the total absorbed ${ }^{14} \mathrm{C}$ in $P$. involutus during a $30 \mathrm{~min}$ incubation period. However, the ${ }^{14} \mathrm{C}$ loss by respiration is probably even less during a $5 \mathrm{~min}$ incubation period since the $\mathrm{CO}_{2}$ evolution was not a linear function of time during the first $10 \mathrm{~min}$ (Chalot $e t$ al., 1994b). The amino acids had the following specific activities : $\mathrm{L}-\left[\mathrm{U}-{ }^{14} \mathrm{C}\right]$ glutamate, $10.4 \mathrm{MBq} \mu \mathrm{mol}^{-1}$; L-[U$\left.{ }^{14} \mathrm{C}\right]$ glutamine, $7.8 \mathrm{MBq} \mu \mathrm{mol}^{-1}$; L- $\left[\mathrm{U}^{14} \mathrm{C}\right]$ alanine, $6.7 \mathrm{MBq}$

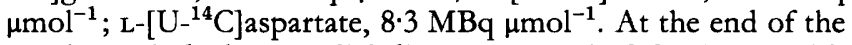
uptake period, the mycelial discs were washed for $2 \mathrm{~min}$ with $0.1 \mathrm{mM} \mathrm{CaSO}_{4}$ and freeze-dried prior to analysis.

Inhibition experiments. In experiments using metabolic inhibitors, the discs were preincubated for $5 \mathrm{~min}$ with the inhibitor prepared in a nitrogen- and glucose-free MMN medium ( $\mathrm{pH} \mathrm{4.2)} \mathrm{and} \mathrm{were} \mathrm{then} \mathrm{transferred} \mathrm{to} \mathrm{a} \mathrm{solution}$ containing the inhibitor and the labelled amino acid, added at a concentration of $10 \mu \mathrm{M}$. Metabolic inhibitors used in the present study have been extensively used by other workers and most of them markedly affected respiration by $P$. involutus, thus demonstrating uptake by the cells. Respiration was measured polarographically at $25^{\circ} \mathrm{C}$ using a Clark $\mathrm{O}_{2}$ electrode according to Pireaux et al. (1995). In experiments using amino acids or amino acid analogues as inhibitors, discs were incubated with the labelled amino acid and the inhibitor. Unless indicated, all amino acids used in inhibition experiments were L-amino acids.

Determination of radioactivity. Fungal tissues were solubilized with Soluene 350 overnight at $55^{\circ} \mathrm{C}$, mixed with $6 \mathrm{ml}$ scintillant (Ionic Fluor) and the radioactivity in the mycelium was measured by liquid scintillation spectroscopy.

Expression of results. Each experiment included three replicates and was repeated at least twice. The $K_{\mathrm{m}}$ and $V_{\max }$ values given in this study were obtained on four to six different occasions. Results are the mean $\pm \mathrm{SE}$. The inhibition data, expressed as a percentage of the control, were arcsintransformed prior to SE calculations.

\section{RESULTS AND DISCUSSION}

\section{Kinetics of uptake}

Amino acid uptake by $P$. involutus was measured at different amino acid concentrations in the range 0.0024 $20 \mathrm{mM}$. The rate of uptake increased with increasing 

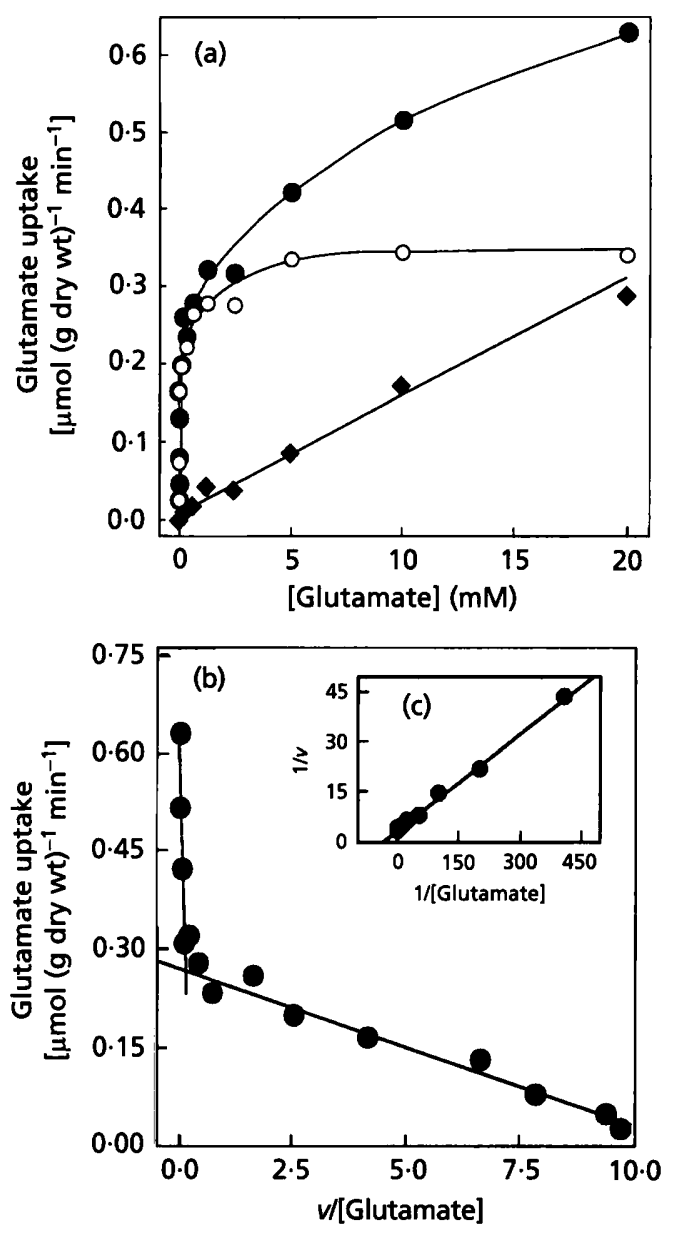

Fig. 1. Effect of substrate concentration on the uptake of glutamate in the absence and presence of DNP by $P$. involutus. Uptake of $\left[{ }^{14} \mathrm{C}\right]$ glutamate from $0.0024-20 \mathrm{mM}$ solutions was assayed alone or in the presence of $10 \mu \mathrm{M}$ DNP under the standard conditions. (a) Uptake occurring in the presence of DNP $(\diamond)$ was subtracted from uptake under non-inhibition conditions (O) for each glutamate concentration, to give the mediated uptake (O). (b) Eadie-Hofstee plot of the concentration-dependence of the uptake. (c) Lineweaver-Burk plot (inset).

substrate concentration but no saturation was observed (Fig. 1a). An Eadie-Hofstee plot ( $v$ against $v / S$ ) of the data revealed biphasic kinetics (Fig. 1b). Similarly, nonsaturable and biphasic kinetics were seen for glutamine, alanine and aspartate (data not shown). This indicated that there are two or more components in the uptake of amino acids by $P$. involutus. At a high amino acid concentration, the rate of uptake was directly proportional to the external amino acid concentration.

In plant tissues, uptake often includes a diffusion component (Schobert \& Komor, 1987). Therefore, the hypothesis that uptake of amino acid by $P$. involutus is partly by a pathway with diffusion-like kinetics was tested. When the uptake of amino acids was estimated in the presence of $10 \mu \mathrm{M}$ DNP (present in the uptake solution, 5 min preincubation), the remaining transport appeared to be identical to the linear component, which was revealed by kinetic analysis of concentration-dependence data in the absence of inhibitors (Fig. 1a). Such a linear component has been observed frequently with plant cells or tissues for uptake of amino acids (Borstlap, 1983; Sopanen \& Väisänen, 1985; Väisänen \& Sopanen, 1986). There are also many examples of transport processes where the concentration dependence of the uptake rate displays a linear component (Borstlap, 1983). Sopanen \& Väisänen (1985) and Väisänen \& Sopanen (1986) have suggested the occurrence of a non-mediated uptake that they have related to the linear component. This will be observed if there is any carryover of incubation medium to the sample of material to be assayed but a linear component may also represent transport across the cell membrane (Borstlap, 1983). The fact that a linear uptake was obtained when incubations were performed with DNP supports strong evidence that the linear component of amino acid uptake was due to a non-mediated diffusionlike uptake. When the uptake under inhibition conditions was subtracted from uptake occurring in the absence of DNP for each glutamate concentration, a saturable mediated uptake was obtained (Fig. 1a) which conformed to simple Michaelis-Menten kinetics.

Values for the Michaelis constants $\left(K_{\mathrm{m}}\right)$ and maximum velocities $\left(V_{\max }\right)$ for the mediated uptake, estimated from the Eadie-Hofstee plot (Fig. 1b), are given in Table 1. Results obtained from calculations with the LineweaverBurk plots (Fig. 1c) are included for comparative purposes (Table 1). The uptake systems for glutamate, glutamine, alanine and aspartate exhibited similar $V_{\max }$ and $K_{\mathrm{m}}$ values. Similar rates have been reported for the uptake of glutamine and proline by scutellum of germinating barley grain (Sopanen \& Väisänen, 1985; Väisänen \& Sopanen, 1986), for the uptake of leucine by S. cerevisiae (Ramos et al., 1980) and for the uptake of glutamate by Penicillium cyclopium (Roos, 1989). The values found for the apparent $K_{\mathrm{m}}$ were similar to those of Roos (1989) for amino acid transport by the general amino acid permease in Pen. cyclopium and to those for methionine transport by mycelia of Fusarium oxysporum (Barran, 1981). However, the $K_{\mathrm{m}}$ values found in the present study are much lower than those found for glutamate uptake by the duckweed Spirodela polyrbiza (Borstlap et al., 1986), for glutamine uptake by the scutellum of germinating barley grain (Sopanen \& Väisänen, 1985) and for alanine uptake by Lemna gibba (Lüttge et al., 1981).

The uptake of $10 \mu \mathrm{M}$ labelled glutamate was assayed in the presence of increasing concentrations of unlabelled glutamate (present in the uptake solution, no preincubation). The unlabelled glutamate almost totally suppressed the uptake of the labelled glutamate (data not shown). However, when the inhibitory effect was extrapolated to an infinitely high concentration of unlabelled amino acid (for calculations, refer to Sopanen \& Väisänen, 1985 ), the extrapolation showed that $4 \cdot 1 \%$ of the uptake of $10 \mu \mathrm{M}\left[{ }^{14} \mathrm{C}\right]$ glutamate was not inhibited by unlabelled glutamate. Similar values were found for glutamine $(3.7 \%)$, alanine $(2.5 \%)$ and aspartate $(3.0 \%)$. This noninhibitable uptake represented the contribution of the non-mediated uptake (Sopanen \& Väisänen, 1985; 
Table 1. Kinetic parameters for uptake of L-glutamate, L-glutamine, L-alanine and L-aspartate by the ectomycorrhizal fungus $P$. involutus

The $K_{\mathrm{m}}$ and $V_{\max }$ values were estimated from the Eadie-Hofstee plots after correction for the nonmediated uptake. The kinetic parameters derived from the Lineweaver-Burk plots are enclosed in parentheses.

\begin{tabular}{|c|c|c|c|}
\hline Amino acid & Optimum pH* & $V_{\max }\left[\mu \mathrm{mol}(\mathrm{gdry} w t)^{-1} \min ^{-1}\right]$ & $K_{\mathrm{m}}(\mu \mathrm{M})$ \\
\hline Glutamate & $3 \cdot 9 \cdot 4 \cdot 3$ & $0.293(0.285)$ & $27 \cdot 0(27 \cdot 0)$ \\
\hline Glutamine & $3 \cdot 9-4 \cdot 3$ & $0.714(0.606)$ & $14.0(11.0)$ \\
\hline Alanine & $4 \cdot 0-5 \cdot 3$ & $0.359(0.364)$ & $7 \cdot 2(7 \cdot 6)$ \\
\hline Aspartate & $4 \cdot 0-5 \cdot 3$ & $0.242(0.284)$ & $14 \cdot 1(24 \cdot 0)$ \\
\hline
\end{tabular}

* From Chalot et al. (1995a).

Table 2. Effects of inhibitors and ionophores on amino acid uptake

The uptake of $10 \mu \mathrm{M}$ labelled amino acids was assayed in the presence of various concentrations of the inhibitors. Discs of fungal inoculum were preincubated for $5 \mathrm{~min}$ with the inhibitor prepared in a nitrogen- and glucose-free MMN medium ( $\mathrm{pH} \mathrm{4.2)} \mathrm{and} \mathrm{then} \mathrm{transferred} \mathrm{to} \mathrm{a} \mathrm{solution} \mathrm{containing} \mathrm{the}$ inhibitor and the labelled amino acid, added at a $10 \mu \mathrm{M}$ concentration. Data are expressed as means \pm SE of three replicates; $100 \%$ uptake for glutamate, glutamine, alanine and aspartate represented $73,40,66$ and $30 \mathrm{nmol}(\mathrm{g} \text { dry wt) })^{-1} \mathrm{~min}^{-1}$, respectively.

\begin{tabular}{|c|c|c|c|c|c|}
\hline \multirow[t]{2}{*}{ Inhibitor* } & \multirow[t]{2}{*}{ Concn $(\mathrm{mM})$} & \multicolumn{4}{|c|}{ Uptake of labelled amino acids (inhibition, \%) } \\
\hline & & Glutamate & Glutamine & Alanine & Aspartate \\
\hline \multirow[t]{2}{*}{ CCCP } & $0 \cdot 01$ & $96.6 \pm 0.9$ & $96 \cdot 0 \pm 1 \cdot 1$ & $95 \cdot 6 \pm 0 \cdot 4$ & $95 \cdot 1 \pm 0 \cdot 1$ \\
\hline & $0 \cdot 10$ & $97 \cdot 9 \pm 0 \cdot 3$ & $97 \cdot 2 \pm 0 \cdot 1$ & $97 \cdot 4 \pm 0 \cdot 1$ & $95 \cdot 6 \pm 0 \cdot 9$ \\
\hline DCCD & $0 \cdot 10$ & $2 \cdot 0 \pm 0 \cdot 6$ & $8 \cdot 8 \pm 2 \cdot 5$ & 0 & $1 \cdot 9 \pm 1 \cdot 0$ \\
\hline \multirow[t]{2}{*}{ DNP } & $0 \cdot 01$ & $98 \cdot 1 \pm 0 \cdot 1$ & $97 \cdot 1 \pm 1 \cdot 2$ & $97 \cdot 6 \pm 0 \cdot 2$ & $97 \cdot 1 \pm 0 \cdot 2$ \\
\hline & $0 \cdot 10$ & $99 \cdot 1 \pm 0 \cdot 2$ & $98.8 \pm 0.6$ & $98 \cdot 6 \pm 0 \cdot 6$ & $97 \cdot 9 \pm 0 \cdot 1$ \\
\hline $\mathrm{KCN}$ & $0 \cdot 10$ & $13 \cdot 6 \pm 2 \cdot 3$ & $9 \cdot 9 \pm 6 \cdot 3$ & $6.5 \pm 1 \cdot 3$ & $11 \cdot 0 \pm 2 \cdot 4$ \\
\hline Monensin & 0.001 & $\overline{0}$ & $\overline{0}$ & $\overline{0}$ & $\overline{0}$ \\
\hline $\mathrm{NaF}$ & $1 \cdot 00$ & $27 \cdot 4 \pm 2 \cdot 4$ & $6 \cdot 1 \pm 1 \cdot 2$ & $37 \cdot 6 \pm 0.4$ & $17 \cdot 3 \pm 3 \cdot 7$ \\
\hline \multirow[t]{2}{*}{$\mathrm{NaN}_{3}$} & $0 \cdot 01$ & $51 \cdot 4 \pm 5 \cdot 4$ & $29 \cdot 2 \pm 5 \cdot 8$ & $25 \cdot 2 \pm 9 \cdot 4$ & $93.5 \pm 0.2$ \\
\hline & $0 \cdot 10$ & $96 \cdot 4 \pm 1 \cdot 1$ & $76 \cdot 0 \pm 0.2$ & $59 \cdot 3 \pm 0 \cdot 1$ & $94 \cdot 6 \pm 1 \cdot 2$ \\
\hline Nonactin & 0.001 & 0 & 0 & 0 & 0 \\
\hline \multirow[t]{2}{*}{ Vanadate } & $0 \cdot 1$ & 0 & 0 & 0 & 0 \\
\hline & $1 \cdot 0$ & 0 & 0 & 0 & 0 \\
\hline
\end{tabular}

* CCCP, DCCD, monensin and nonactin were dissolved in ethanol (final concentration $1 \%, \mathrm{v} / \mathrm{v}$ ).

Väisänen \& Sopanen, 1986) and the values found were quite similar to those found for uptake in the presence of the inhibitors DNP or CCCP (Table 2).

\section{Effect of metabolic inhibitors}

Data in Table 2 show that CCCP and DNP (present in the uptake solution, $5 \mathrm{~min}$ preincubation) were the most effective inhibitors of amino acid transport by $P$. involutus (see also Fig. 1a). The inhibitory effect of these substances on amino acid uptake was detectable within $5 \mathrm{~min}$ in $P$. involutus. Despeghel \& Delrot (1983) reported that DNP and CCCP strongly inhibited amino acid uptake by mesophyll cells within $10 \mathrm{~min}$. Amino acid transport by barley leaves (Lien \& Rognes, 1977), Asparagus mesophyll cells (McCutcheon \& Bown, 1987), S. cerevisiae (Ramos et al., 1980), F. oxysporum (Barran, 1981) and Pen. cyclopium (Roos, 1989) was also strongly inhibited by DNP and/or CCCP. The presence of $\mathrm{NaN}_{3}$ also gave moderate inhibition. A similar inhibitory effect of $\mathrm{NaN}_{3}$ has been demonstrated for methionine uptake by $F$. oxysporum (Barran, 1981). Nonactin, a $\mathrm{K}^{+}$-ionophore (Steverding \& Kadenbach, 1990), and monensin, a $\mathrm{Na}^{+}$-ionophore (Sandeaux et al., 1982), did not affect the transport of amino acids. The ATPase inhibitors DCCD and vanadate also did not affect amino acid uptake. The glycolysis inhibitor $\mathrm{NaF}$, at a high concentration, and the respiratory inhibitor KCN exerted a marginal inhibition of glutamate, 
Table 3. Uptake of L-glutamate, L-glutamine, L-alanine and L-aspartate in the presence of various inhibitors

The uptake of $10 \mu \mathrm{M}$ labelled amino acids was assayed in the presence of increasing concentrations of inhibitors. Discs were incubated in a solution containing the labelled amino acid, added at $10 \mu \mathrm{M}$, and the inhibitor. Data are expressed as means \pm SE of three replicates; $100 \%$ uptake for glutamate, glutamine, alanine and aspartate ranged from 35 to 102,59 to 106,49 to 158,24 to $49 \mathrm{nmol}$ (g dry $\mathrm{wt})^{-1} \mathrm{~min}^{-1}$, respectively. ND, Not determined in this experiment.

\begin{tabular}{|c|c|c|c|c|c|}
\hline \multirow[t]{2}{*}{ Inhibitor } & \multirow[t]{2}{*}{ Concn $(\mathrm{mM})$} & \multicolumn{4}{|c|}{ Uptake of labelled amino acids (inhibition, \%) } \\
\hline & & Glutamate & Glutamine & Alanine & Aspartate \\
\hline Alanine & $0 \cdot 25$ & $92 \cdot 6 \pm 1 \cdot 2$ & $94.4 \pm 0.4$ & ND & $94 \cdot 2 \pm 0 \cdot 2$ \\
\hline AOA & $0 \cdot 25$ & $74 \cdot 7 \pm 1 \cdot 4$ & $63.9 \pm 0.2$ & $46 \cdot 9 \pm 3 \cdot 3$ & $79 \cdot 8 \pm 0 \cdot 2$ \\
\hline Arginine & $0 \cdot 50$ & $83.9 \pm 1.5$ & $81 \cdot 9 \pm 0 \cdot 7$ & $61 \cdot 7 \pm 0 \cdot 8$ & $92 \cdot 4 \pm 0 \cdot 4$ \\
\hline Asparagine & 0.50 & $95 \cdot 7 \pm 0 \cdot 2$ & $94 \cdot 9 \pm 1 \cdot 4$ & $90 \cdot 4 \pm 2 \cdot 6$ & $96 \cdot 4 \pm 0 \cdot 4$ \\
\hline Aspartate & 0.25 & $56 \cdot 9 \pm 1 \cdot 1$ & $76 \cdot 8 \pm 0 \cdot 1$ & $68 \cdot 6 \pm 2 \cdot 6$ & ND \\
\hline ALB & 0.25 & $42 \cdot 3 \pm 6 \cdot 8$ & $46.9 \pm 1.6$ & $23.4 \pm 0.6$ & $66 \cdot 0 \pm 7 \cdot 0$ \\
\hline Glutamate & $0 \cdot 25$ & ND & $88 \cdot 6 \pm 0.2$ & $84.0 \pm 0.4$ & $89.9 \pm 0.7$ \\
\hline Glutamine & 0.25 & $86.9 \pm 0.1$ & ND & $86.4 \pm 0.7$ & $92 \cdot 8 \pm 0 \cdot 4$ \\
\hline D-Glutamine & 0.50 & $86.5 \pm 0.5$ & $83.8 \pm 3.0$ & $57 \cdot 2 \pm 5 \cdot 3$ & $90.7 \pm 0.6$ \\
\hline Glycine & $0 \cdot 50$ & $97 \cdot 8 \pm 0 \cdot 8$ & $97 \cdot 4 \pm 0 \cdot 7$ & $95 \cdot 9 \pm 1 \cdot 3$ & $96 \cdot 7 \pm 0 \cdot 4$ \\
\hline Leucine & 0.50 & $98 \cdot 6 \pm 1 \cdot 0$ & $97 \cdot 6 \pm 1 \cdot 0$ & $98.0 \pm 0.7$ & $96.9 \pm 0.2$ \\
\hline Lysine & $0 \cdot 50$ & $93 \cdot 0 \pm 0.4$ & $93 \cdot 5 \pm 1 \cdot 2$ & $87 \cdot 8 \pm 2 \cdot 5$ & $94 \cdot 3 \pm 0.7$ \\
\hline Methionine & $0 \cdot 50$ & $99 \cdot 2 \pm 0 \cdot 2$ & $98 \cdot 1 \pm 1 \cdot 0$ & $98 \cdot 2 \pm 0 \cdot 1$ & $96.9 \pm 0.3$ \\
\hline MSX & $0 \cdot 25$ & $57 \cdot 1 \pm 0 \cdot 4$ & $36 \cdot 1 \pm 2 \cdot 5$ & $39 \cdot 0 \pm 1 \cdot 2$ & $72.5 \pm 0.8$ \\
\hline Norleucine & 0.50 & $98 \cdot 8 \pm 0.4$ & $97 \cdot 7 \pm 0 \cdot 1$ & $97 \cdot 7 \pm 1 \cdot 2$ & $98 \cdot 1 \pm 0 \cdot 3$ \\
\hline Serine & 0.50 & $96.9 \pm 2.6$ & $97 \cdot 7 \pm 1 \cdot 3$ & $96.9 \pm 0.3$ & $96 \cdot 9 \pm 0 \cdot 1$ \\
\hline Tryptophan & 0.50 & $96.9 \pm 0.4$ & $97 \cdot 4 \pm 0 \cdot 1$ & $88 \cdot 3 \pm 1 \cdot 8$ & $96 \cdot 4 \pm 1.5$ \\
\hline
\end{tabular}

glutamine, alanine and aspartate uptake. These findings indicate that an electrochemical gradient of protons is necessary for the uptake of amino acids, whereas hydrolysis of ATP is not the direct driving force for the uptake process.

The uptake of amino acid at micromolar concentrations was performed against a gradient of several orders of magnitude (in the case of glutamate and glutamine we have determined the cytoplasmic concentration to be in the millimolar range in $P$. involutus). Therefore, the uptake of amino acids in $P$. involutus must be an active process. DNP and CCCP principally act as protonophores and therefore deplete the protonmotive force by increasing $\mathrm{H}^{+}$influx and thereby inducing acidification of the cytosol (Despeghel \& Delrot, 1983; Kasianowicz et al., 1984). The depression of amino acid transport by the presence of the metabolic inhibitor $\mathrm{NaN}_{3}$ was expected from studies showing that this compound reduces the proton gradient; for instance, Spanswick \& Miller (1977) have shown that in Nitella, $\mathrm{NaN}_{3}$ reduces the internal $\mathrm{pH}$ by as much as 1-2 units. Furthermore, the uptake of amino acids in $P$. involutus markedly depended on the $\mathrm{pH}$ and was optimal at $\mathrm{pH} 3.9-4.3$ for glutamate and glutamine, and at pH 3.9-5.0 for alanine and aspartate (Chalot et al., 1995a). The stimulation of amino acid uptake by acidic $\mathrm{pH}$ values has already been noticed in various organisms (Despeghel \& Delrot, 1983; Johannes \& Felle, 1985; Roos, 1989).
The amino acid transporter from $P$. involutus might therefore function as a $\mathrm{H}^{+}$/symporter, as already demonstrated for amino acid permeases from plants (Etherton \& Rubinstein, 1978; Lüttge et al., 1981; McCutcheon \& Bown, 1987; Snedden et al., 1992; Bush, 1993), yeast (Wiame et al., 1985) and other fungi (Sanders et al., 1983; Roos, 1989). The uptake of glutamate, glutamine, alanine or aspartate took place in nutritive medium without any added $\mathrm{Na}^{+}, \mathrm{K}^{+}$or $\mathrm{Ca}^{2+}$, and increasing the concentrations of $\mathrm{Na}^{+}$or $\mathrm{Ca}^{2+}$ by two orders of magnitude compared with the normal MMN medium did not significantly modify the uptake (data not shown). These results, together with the lack of inhibitory effect of the ionophores nonactin and monensin (Table 2), indicate that these cations do not take part in the uptake.

$\mathrm{H}^{+}$-coupled transport can be maintained only if the breakdown of the energizing protonmotive force by the cotransported protons is prevented, either by their continuous extrusion via the proton-translocating ATPase, or by charge-compensating fluxes of other ions. DCCD and vanadate, which are known to inhibit electrogenic proton translocation by $\mathrm{H}^{+} /$ATPase and $\mathrm{F}_{1} \mathrm{~F}_{0}$ ATPase (Marre \& Ballarin-Denti, 1985) in the plasma membrane of fungi, had no effect on amino acid uptake by $P$. involutus during the $5 \mathrm{~min}$ incubation. The absence of any effect of these inhibitors seems to rule out the direct involvement of the $\mathrm{H}^{+}$-ATPase. Despeghel \& 


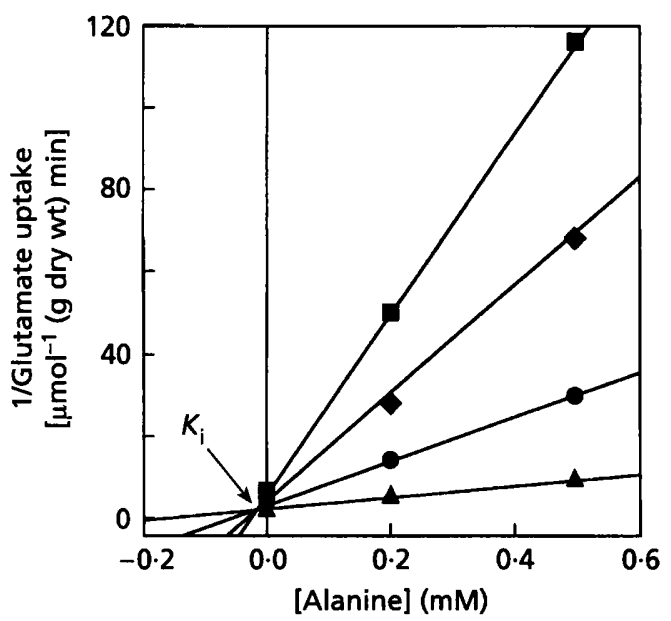

Fig. 2. Dixon plots of the inhibition of glutamate uptake by alanine. Glutamate concentrations were $0.015(\square), 0.031(\bullet)$, 0.062 (O) and 0.25 (A) $\mathrm{mM}$. Alanine was added at concentrations of 0.2 and $0.5 \mathrm{mM}$ or omitted. The reciprocal uptake rate is plotted against the competitor concentration.

Delrot (1983) have shown that $0 \cdot 1 \mathrm{mM}$ DCCD inhibited amino acid uptake only after $30 \mathrm{~min}$. However, DCCD inhibited $\mathrm{O}_{2}$ consumption by $55 \%$ within $2 \mathrm{~min}$ incubation in $P$. involutus, thus demonstrating that the inhibitor was taken up by the cells. $P$. involutus excretes significant amounts of $\mathrm{H}^{+}$, together with dicarboxylate anions, mainly oxalic acid (Lapeyrie et al., 1987), and the extrusion of organic acids might be involved in the maintenance of the intracellular $\mathrm{pH}$, as suggested by Roos \& Luckner (1984) for Pen. cyclopium grown in the absence of ammonia.

\section{Amino acid specificity}

A first set of inhibition experiments (inhibitors present in the uptake solution, no preincubation) was done at a low concentration of labelled amino acid $(10 \mu \mathrm{M})$, where at least $94-98 \%$ of the uptake was by the saturable system. Glutamate, glutamine, alanine and aspartate inhibited the uptake of each other by more than $80 \%$ at $0.25 \mathrm{mM}$ (Table 3), and by more than $92 \%$ at $2.5 \mathrm{mM}$ (data not shown). However, aspartate was a poor competitor at lower concentrations; for instance, $25 \mu \mathrm{M}$ glutamate inhibited aspartate uptake by $76.8 \%$, whereas the same concentration of aspartate inhibited glutamate uptake by only $9 \cdot 4 \%$. Similarly, uptake of the four amino acids tested was inhibited by more than $90 \%$ at $0.5 \mathrm{mM}$ glycine, asparagine, leucine, norleucine, methionine, serine or tryptophan (Table 3). The basic amino acids arginine and lysine and the D-analogue of glutamine also had a marked, but less pronounced, inhibitory effect. The uptake of the four amino acids tested was also strongly inhibited by methionine sulfoximine (MSX), albizziin (ALB) and aminooxyacetate $(\mathrm{AOA})$ (Table 3 ), which are well-known inhibitors of nitrogen-assimilating enzymes (Chalot $e t$ al., 1994a). However, the inhibitory effect of these analogues

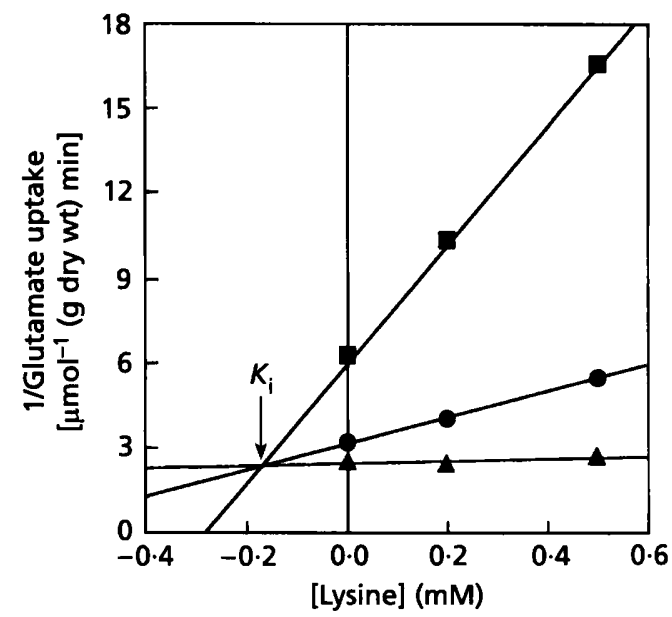

Fig. 3. Dixon plots of the inhibition of glutamate uptake by lysine. Glutamate concentrations were $0.031(\square), 0.25(0)$ and $0.50(\Delta) \mathrm{mM}$. Lysine was added at concentrations of 0.2 and $0.5 \mathrm{mM}$ or omitted. The reciprocal uptake rate is plotted against the competitor concentration.

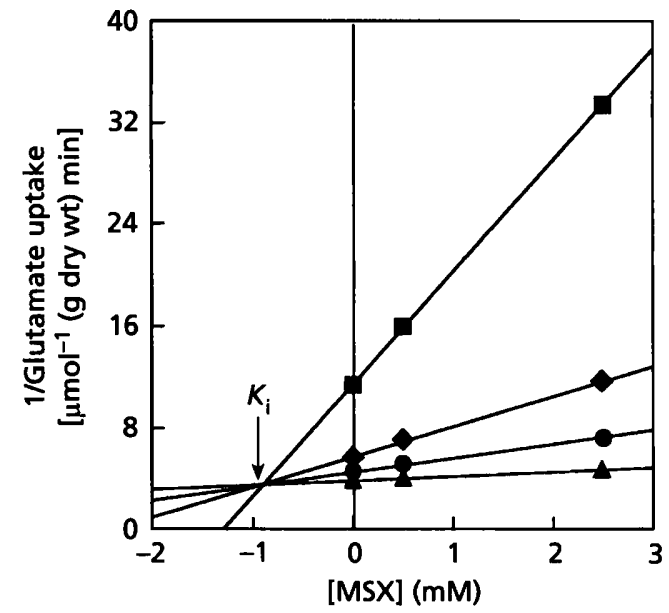

Fig. 4. Dixon plots of the inhibition of glutamate uptake by MSX. Glutamate concentrations were $0.008(\square), 0.031(\diamond)$, $0.062(O)$ and $0.125(\Delta) \mathrm{mM}$. MSX was added at concentrations of 0.5 and $2.5 \mathrm{mM}$ or omitted. The reciprocal uptake rate is plotted against the competitor concentration.

was less pronounced than that of amino acids; for instance, $0.25 \mathrm{mM}$ MSX inhibited glutamine uptake by $36.1 \%$, whereas the same concentration of glutamate inhibited glutamine uptake by $88.6 \%$. Similarly, MSX inhibited glutamate uptake by Asparagus mesophyll cells by $40 \%$ (McCutcheon \& Bown, 1987). Dixon plots of the inhibition of glutamate uptake by alanine (Fig. 2), lysine (Fig. 3) and MSX (Fig. 4) showed that inhibitions were competitive. However, the inhibition constants $\left(K_{i}\right)$ greatly differed between the inhibitors tested, with the $K_{\mathrm{i}}$ for alanine $(0.011 \mathrm{mM})$ being close to its $K_{\mathrm{m}}$ value, whereas those for lysine $(0.180 \mathrm{mM})$ and MSX $(0.90 \mathrm{mM})$ were much greater. 
In most higher plant and fungal tissues, the uptake of one amino acid is inhibited by all or most of the other amino acids tested, and therefore the presence of at least one carrier with a broad specificity has been clearly demonstrated (Sauer \& Tanner, 1985; Wiame et al., 1985; Bush, 1993). The similarity of the $K_{\mathrm{m}}$ value for alanine uptake and its $K_{\mathbf{i}}$ value for the inhibition of glutamate uptake shows that alanine and glutamate are transported by the same carrier. Similarly, amino acid analogues, such as MSX, ALB and AOA, were powerful uptake inhibitors, showing the lack of specificity of the transport system. These inhibitions could be overcome by increasing glutamate concentrations (data not shown), which points to a competition for uptake rather than a non-specific influence on the carrier activity. Indeed, the kinetics of inhibition showed that glutamate and MSX compete for the same binding site. Furthermore, in an earlier paper, we have shown that the inhibitory effect of MSX was rapidly overcome by the mycelium when $P$. involutus was preincubated with MSX and further incubated with $\left[{ }^{14} \mathrm{C}\right]$ glutamate (Chalot et al., 1994a), thus demonstrating that the effect of MSX is not due to possible nonreversible binding or inactivation. An experiment with $\left[{ }^{14} \mathrm{C}\right] \mathrm{MSX}$ has shown that addition of L-glutamine to the medium interfered with MSX uptake in a competitive fashion (Meins \& Abrams, 1972). The authors concluded from these data that MSX and glutamine competed for a common carrier. Amino acid uptake in P. involutus also lacked stereospecificity, as D-glutamine was a strong inhibitor. The general amino acid transporter from $P$. involutus resembles the amino acid permease of yeast, which has more than 20 natural substrates, including most L- and D-amino acids, non-protein amino acids and a number of toxic amino acid analogues or amino acid biosynthesis inhibitors (Wiame et al., 1985; Horak, 1986; Roos, 1989; Sophianopoulou \& Diallinas, 1995). This work does not provide evidence for additional transport systems in P. involutus.

\section{Concluding remarks}

Transport studies with symbiotic micro-organisms such as ectomycorrhizal fungi may be of particular importance. Studies of nitrogen metabolism in ectomycorrhizas have demonstrated that the fungal symbiont plays a fully integrated role in plant root metabolism and participates actively in the assimilation and transfer of newly absorbed nitrogen compounds (Finlay et al., 1989; Chalot et al., 1991; Martin \& Botton, 1993; Botton \& Chalot, 1995). The present investigations were performed with $P$. involutus cultivated separately from its host plant; therefore, it remains to be established to what extent these uptake processes apply to the symbiotic relationship. Smith \& Smith (1989), in their review on membrane transport at the biotrophic interface, concluded that the overall question to be considered in mutualistic symbioses is whether nutrient transfer processes have analogies elsewhere in the physiology of plants or whether new transport events are switched on as a result of interactions between the organisms. It is evident, from studies of ectomycorrhizal development, that structural and func- tional integration of the root and fungus can take place very rapidly and further experiments will be directed to elucidate nitrogen transport mechanisms at the biotrophic interface.

\section{ACKNOWLEDGEMENTS}

This work was supported by a grant (ERB-EV5V-CT-93-5204) from the Commission of the European Communities to M.C. Financial support from the Swedish Natural Science Research Council and the Swedish Council for Forestry and Agricultural Research are gratefully acknowledged. The authors wish to thank unknown referees for their helpful comments.

\section{REFERENCES}

Abuarghub, S. M. \& Read, D. J. (1988). The biology of mycorrhiza in the Ericaceae. XII. Quantitative analysis of individual free amino acids in relation to time and depth in the soil profile. New Pbytol 108, 433-441.

Abuzinadah, R. A. \& Read, D. J. (1986). The role of proteins in the nitrogen nutrition of ectomycorrhizal plants. I. Utilization of peptides and proteins by ectomycorrhizal fungi. New Pbytol 103, 481-493.

Abuzinadah, R. A. \& Read, D. J. (1988). Amino acids as nitrogen sources for ectomycorrhizal fungi. Trans Br Mycol Soc 91, 473-479.

Barran, L. R. (1981). Methionine transport by mycelia of Fusarium oxysporum f. sp. lycopersici. Can J Microbiol 27, 743-747.

Borstlap, A. C. (1983). The use of model-fitting in the interpretation of dual uptake isotherms. Plant Cell Environ 6, 407-416.

Borstlap, A. C., Meenks, J. L. D., Van Eck, W. F. \& Bicker, J. T. E. (1986). Kinetics and specificity of amino acid uptake by the duckweed Spirodela polyrhiza (L.). Schleiden. $J$ Exp Bot 37, 1020-1035.

Botton, B. \& Chalot, M. (1995). Nitrogen assimilation: enzymology in ectomycorrhizas. In Mycorrbiza: Structure, Function, Molecular Biology and Biotechnology, pp. 325-363. Edited by B. Hock \& A. Varma. Heidelberg: Springer-Verlag.

Bush, D. R. (1993). Proton-coupled sugar and amino acid transporters in plants. Annu Rev Plant Pbysiol Plant Mol Biol 44, 513-542.

Chalot, M., Stewart, G. R., Brun, A., Martin, F. \& Botton, B. (1991). Ammonium assimilation by spruce-Hebeloma sp. ectomycorrhizas. New Pbytol 119, 541-550.

Chalot, M., Brun, A., Finlay, R. D. \& Söderström, B. (1994a). Metabolism of $\left[{ }^{14} \mathrm{C}\right]$ glutamate and $\left[{ }^{14} \mathrm{C}\right]$ glutamine by the ectomycorrhizal fungus Paxillus involutus. Microbiology 140, 1641-1649.

Chalot, M., Brun, A., Finlay, R. D. \& Söderström, B. (1994b). Respiration of $\left[{ }^{14} \mathrm{C}\right]$ alanine by the ectomycorrhizal fungus Paxillus involutus. FEMS Microbiol Lett 121, 87-92.

Chalot, M., Kytoviita, M. M., Brun, A., Finlay, R. D. \& Söderström, B. (1995a). Factors affecting amino acid uptake by the ectomycorrhizal fungus Paxillus involutus. Mycol Res 99, 1131-1138.

Chalot, M., Finlay, R. D., Ek, H. \& Söderström, B. (1995b). Metabolism of $\left[{ }^{15} \mathrm{~N}\right]$ alanine in the ectomycorrhizal fungus Paxillus involutus. Exp Mycol 19, 297-304.

Despeghel, J. P. \& Delrot, S. (1983). Energetics of amino acid uptake by Vicia faba leaf tissues. Plant Physiol 71, 1-6.

Etherton, B. \& Rubinstein, B. (1978). Evidence for amino acid $\mathrm{H}^{+}$ co-transport in oat coleoptiles. Plant Pbysiol 61, 933-937.

Finlay, R. D., Ek, H., Odham, G. \& Söderström, B. (1989). Uptake, translocation and assimilation of nitrogen from ${ }^{15} \mathrm{~N}$-labelled 
ammonium and nitrate sources by intact ectomycorrhiza systems infected with Paxillus involutus. New Pbytol 113, 47-55.

Finlay, R. D., Frostegård, Å. \& Sonnerfeldt, A. M. (1992). Utilization of organic and inorganic nitrogen sources by ectomycorrhizal fungi in pure culture and in symbiosis with Pinus contorta Dougl. ex Loud. New Pbytol 120, 105-115.

Frommer, W. B., Kwart, M., Hirner, B., Fischer, W. N., Hummel, S. \& Ninnemann, O. (1994). Transporters for nitrogenous compounds in plants. Plant Mol Biol 26, 1651-1670.

Horak, J. (1986). Amino acid transport in eukaryotic microorganisms. Biocbim Biophys Acta 864, 223-256.

Johannes, E. \& Felle, H. (1985). Transport of basic amino acids in Riccia fluitans: evidence for a second binding site. Planta 166, 244-251.

Kasianowicz, J., Benz, R. \& McLaughlin, S. (1984). The kinetic mechanism by which CCCP (carbonyl cyanide- $m$-chlorophenylhydrazone) transports protons across membranes. J Membr Biol 82, 179-190.

Lapeyrie, F., Chilvers, G. A. \& Bhem, C. A. (1987). Oxalic acid synthesis by the mycorrhizal fungus Paxillus involutus (Batsch. ex Fr.) Fr. New Pbytol 106, 139-146.

Lien, R. \& Rognes, S. E. (1977). Uptake of amino acids by barley leaf slices : kinetics, specificity, and energetics. Physiol Plant 41, 175-183.

Luttge, U., Jung, J. D. \& Ullrich-Eberius, C. I. (1981). Evidence for amino-acid- $\mathrm{H}^{+}$cotransport in Lemna gibba given by effects of fusicoccin. Z Pfanzenphysiol 102, 117-125.

Marre, E. \& Ballarin-Denti, A. (1985). The proton pumps of the plasmalemma and the tonoplast of higher plants. J Bioenerg Biomembr 17, 1-21.

Martin, F. \& Botton, B. (1993). Nitrogen metabolism of ectomycorrhizal fungi and ectomycorrhiza. Adv Plant Patbol 9, 83-102.

Marx, D. H. (1969). The influence of ectotrophic mycorrhizal fungi on the resistance of pine roots to pathogenic infections. I. Antagonism of mycorrhizal fungi to root pathogenic fungi and soil bacteria. Phytopathology 59, 159-163.

McCutcheon, S. L. \& Bown, A. W. (1987). Evidence for a specific glutamate $/ \mathrm{H}^{+}$cotransport in isolated mesophyll cells. Plant Pbysiol 83, 691-697.

Meins, J. F. \& Abrams, M. L. (1972). How methionine and glutamine prevent inhibition of growth by methionine sulfoximine. Biochim Biopbys Acta 266, 307-311.

Pireaux, J. C., Hayani-Obeidou, W., Chalot, M., Botton, B. \& Dizengremel, P. (1995). Mitochondria in the white-rot fungus Pbanerochaete chrysosporium: purification and evidence for a mitochondrial isoform of aspartate aminotransferase. Exp Mycol 19, 91-100.
Ramos, E. H., De Bongioanni, L. C. \& Stoppani, A. O. M. (1980). Kinetics of L- $\left[{ }^{14} \mathrm{C}\right]$ leucine transport in Saccharomyces cerevisiae. Effect of energy coupling inhibitors. Biocbim Biopbys Acta 599, 214-231.

Roos, W. (1989). Kinetic properties, nutrient-dependent regulation and energy coupling of amino acid transport systems in Penicillium cyclopium. Biochim Biophys Acta 978, 119-133.

Roos, W. \& Luckner, M. (1984). Relationships between proton extrusion and fluxes of ammonium ions and organic acids in Penicillium cyclopium. J Gen Microbiol 130, 1007-1014.

Sandeaux, R., Sandeaux, J., Gavach, C. \& Brun, B. (1982). Transport of $\mathrm{Na}^{+}$by monensin across bimolecular lipid membranes. Biocbim Biophys Acta 684, 127-132.

Sanders, D., Slayman, C. L. \& Pall, M. L. (1983). Stoichiometry of $\mathrm{H}^{+} /$amino acid cotransport in Neurospora crassa revealed by currentvoltage analysis. Biocbim Biophys Acta 735, 67-76.

Sauer, N. \& Tanner, W. (1985). Selection and characterization of Cblorella mutants deficient in amino acid transport. Further evidence for three independent systems. Plant Physiol 79, 760-764.

Schobert, C. \& Komor, E. (1987). Amino acid uptake by Ricinus communis roots: characterization and physiological significance. Plant Cell Environ 10, 493-500.

Smith, F. A. \& Smith, S. E. (1989). Membrane transport at the biotrophic interface: an overview. Aust J Plant Pbysiol 16, 33-43.

Snedden, W. A., Chung, I., Pauls, R. H. \& Bown, A. W. (1992). Proton/L-glutamate symport and the regulation of intracellular $\mathrm{pH}$ in isolated mesophyll cells. Plant Physiol 99, 665-671.

Sopanen, T. \& Väisanen, E. (1985). Uptake of glutamine by the scutellum of germinating barley grain. Plant Physiol 78, 684-689.

Sophianopoulou, V. \& Diallinas, G. (1995). Amino acid transporters of lower eukaryotes: regulation, structure and topogenesis. FEMS Microbiol Rev 16, 53-75.

Spanswick, R. M. \& Miller, A. G. (1977). Measurement of the cytoplasmic $\mathrm{pH}$ in Nitella translucens. Comparison of values obtained by microelectrode and weak acid methods. Plant Physiol 59, 664-666.

Steverding, D. \& Kadenbach, B. (1990). The $\mathrm{K}^{+}$-ionophore nonactin and valinomycin interact differently with the protein of reconstituted cytochrome $c$ oxidase. J Bioenerg Biomembr 22, 197-205.

Vaisanen, E. \& Sopanen, T. (1986). Uptake of proline by the scutellum of germinating barley grain. Plant Pbysiol 80, 902-907.

Wiame, J. M., Grenson, M. \& Arst, H. N. (1985). Nitrogen catabolic repression in yeast and filamentous fungi. Adv Microb Pbysiol 26, $1-88$.

Received 5 December 1995; revised 2 February 1996; accepted 5 February 1996. 